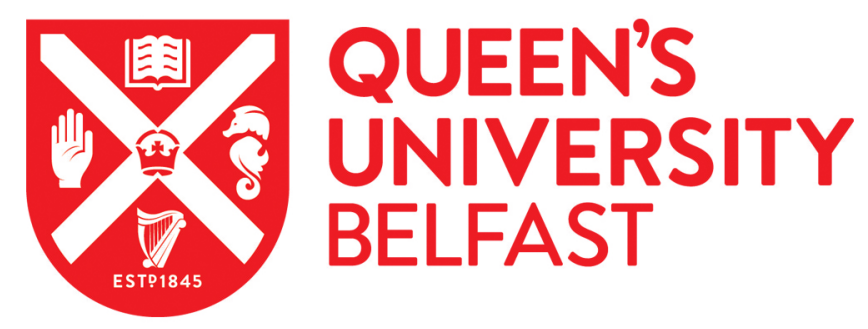

\title{
Living with Life-Limiting Illness: Exploring the Narratives of Patients with Advanced Lung Cancer and Identifying How Social Workers Can Address Their Psycho-Social Needs
}

Roulston, A., Davidson, G., Kernohan, G., \& Brazil, K. (2018). Living with Life-Limiting Illness: Exploring the Narratives of Patients with Advanced Lung Cancer and Identifying How Social Workers Can Address Their Psycho-Social Needs. British Journal of Social Work, 48(7), 2114-2131. https://doi.org/10.1093/bjsw/bcx147

Published in:

British Journal of Social Work

Document Version:

Peer reviewed version

Queen's University Belfast - Research Portal:

Link to publication record in Queen's University Belfast Research Portal

Publisher rights

(c) 2017 The Author.

This work is made available online in accordance with the publisher's policies. Please refer to any applicable terms of use of the publisher.

\section{General rights}

Copyright for the publications made accessible via the Queen's University Belfast Research Portal is retained by the author(s) and / or other copyright owners and it is a condition of accessing these publications that users recognise and abide by the legal requirements associated with these rights.

\section{Take down policy}

The Research Portal is Queen's institutional repository that provides access to Queen's research output. Every effort has been made to ensure that content in the Research Portal does not infringe any person's rights, or applicable UK laws. If you discover content in the

Research Portal that you believe breaches copyright or violates any law, please contact openaccess@qub.ac.uk. 


\title{
Living with life-limiting illness: exploring the narratives of patients with advanced lung cancer and identifying how social workers can address their psychosocial needs.
}

\begin{abstract}
Lung cancer is common in males as well as females and is one of the most common causes of cancer related deaths worldwide. To gain an in-depth understanding of the "pedagogy of suffering' (Frank, 1995: 145), the lived experiences of 12 adult patients in Northern Ireland diagnosed with advanced lung cancer were captured during two qualitative interviews with each patient (one month apart), which were audio-recorded. This article outlines analysis which used Frank's (1995) narrative structures of restitution, chaos and quest, to provide rich insights into how patients narrated their 'suffering' over time. Findings revealed frustration and loss of faith in medical physicians due to a delayed diagnosis; resignation regarding treatment options and outcomes; externalisation of a disease that society fears, curbs life expectancy and causes biographical disruption; and powerlessness underpinned by a heroic return to put affairs in order, encourage others and share hopes for the future. In an era of health and social work practitioners experiencing increasing bureaucracy and caseloads, these findings highlight the importance of prioritising the psychosocial needs of patients, supporting patients with the emotional and practical challenges of living with a life-limiting illness, and of skilful practitioners promoting peaceful closure in end of life care.
\end{abstract}




\section{Living with life-limiting illness: exploring the narratives of patients with advanced lung cancer and identifying how social workers can address their psychosocial needs.}

\section{Introduction}

Cancer is the leading cause of death worldwide, with lung cancer being common in males and females (Cancer Research UK, 2015). In Northern Ireland, there were 1,212 new cases of lung cancer in 2013, and 957 lung cancer deaths with most being diagnosed with advanced disease and only $30 \%$ of those diagnosed surviving one year (NICR, 2013). Lung cancer was selected as it is one of the most common causes of cancer death in Northern Ireland, is not gender specific, is often diagnosed at an advanced stage, and there is a paucity of local lung cancer research.

\section{Timely diagnostics}

Respecting the centrality of time to decision-making processes; effective risk management; and enabling individuals to explore relevant treatment or care options and consequences (Bekker, 2009) is vital, particularly given how time controls our physical biographies and reminds us of our mortality (Durkheim, 1961) which 'imparts an urgent need to value our use of time' (Wahidin, 2004). Time is ordered, sequential and travels in one direction and once lost, it cannot be recaptured (Rabinach, 1992). This emphasises the importance of diagnosing and treating life-threatening illnesses in a timely way, of enabling patients and families to make the best use of time and ensuring that quality of life is maximised. Rutherford, 
McAuley and Fitzsimons (2008) indicated that the lives of patients with lung cancer were pervaded with increased feelings of loss, unfamiliarity, insecurity and vulnerability, which impacted on coping with everyday life and created difficulties with past, present and future decisions.

\section{Communication}

Although $97 \%$ of dying patients realise they are dying, only $40 \%$ initiate conversations about end of life (Ramondetta et al., 2004). Barriers to effective physician-patient communication occur due to: assumptions regarding patient's perceptions and preferences (Desharnais et al., 2007); lack of time (Deschepper et al., 2007); best treatment and care being unknown (Willard and Luker, 2006); or patients not being ready to received in-depth information pertaining to their illness (Ramondetta et al., 2004). Skilful and competent physicians need to facilitate timely and sensitive conversations with patients and family carers regarding end of life issues (Ramondetta et al., 2004; Deschepper et al., 2007). Although most social workers are skilled in providing emotional support, which is pivotal to addressing the psychosocial needs of dying patients and to facilitating peaceful closure in end of life care (Baker, 2006), this crucial aspect of their role is often neglected and overshadowed by how social work is portrayed in the media. 


\section{Decision-making}

Despite palliative care and death being perceived as 'taboo' topics and seldom discussed comfortably within society (McIlfatrick et al., 2014), individuals approaching end-of-life need opportunities to discuss immediate goals, future hopes and prepare for end-of-life, particularly in case mental capacity is lost (Martin, Emmanuel and Singer, 2000; Briggs, 2003). Influenced by the End of Life Care Strategy (DH, 2008) Advance Care Planning (ACP) enables patients to discuss such issues and offers the opportunity for 'shared-decision making' in health care (Elwyn et al., 2000). However decisions confronting patients with lung cancer are fraught with challenges, particularly when weighing up the risk of toxicities against quality of life, side-effects, risks and possible benefits (Siminoff et al., 2006). It is important to understand how an illness affects each patient and what illness, life and death mean to that individual (Winkler et al., 2013) as this enables insight into the patient's values, priorities, preferences and expectations regarding the treatment and care of their illness, which will undoubtedly impact upon their ability to process their 'biographical disruption' (Bury, 1982) whereby the onset of disease disrupts hopes and plans for the future.

The aim of this study was to use Frank's (1995) narrative structures to undertake an in-depth exploration of the 'pedagogy of suffering' of patients living with advanced lung cancer during the last few months of their lives. 


\section{Methodology}

Study design and ethical considerations

These findings are derived from a qualitative study which explored end-of-life care decision making by patients diagnosed with advanced lung cancer and their professional caregivers. This manuscript outlines how Frank’s narrative analysis (Frank, 1995) was used to conduct close, line-by-line analysis of the language used by each participant and to identify the different narratives each patient used to explore their experiences of diagnosis and changes associated with illness progression.

Prior to recruitment, full ethical approval was obtained from the Office for Research Ethics Northern Ireland (Ref: 11/NI/0037), the Health and Social Care Trust and the host university. All participants provided written consent prior to their initial interview. Given the sensitive nature of the interviews and the vulnerability of the population, ethical considerations such as giving assurance of confidentiality, seeking consent to audio-record interviews, clarifying the subsequent management and use of data, highlighting the right to pause or terminate the interview at any time, and ensuring that if participants became distressed, follow-up support through the community palliative care team would be arranged.

\section{Participants}


Participants were recruited from one Health and Social Care Trust in an urban area of Northern Ireland (NI) with a population of 79,000 people (4.36\% of total population).

Standardised mortality ratios were higher than the NI average and incidence rates higher in socio-economically deprived areas (NICR, 2016). All participants were: patients diagnosed with lung cancer and known to the community specialist palliative care team during a seven month period. At weekly multi-disciplinary meetings, all patients were screened by the medical consultant and palliative care nurse specialists against agreed inclusion criteria (i.e. deemed capable of providing informed consent, aware of diagnosis and fluent in English) and exclusion criteria (i.e. unaware of diagnosis, involved in clinical trials or too unwell to participate). During the next clinical appointment, those eligible were offered an invitation letter, participant information sheet (PIS) and consent form. During recruitment thirty-eight patients were screened. Twenty-six were excluded (see Table 1) and twelve (6 male, 6 female) were recruited. Patients' ages ranged from 57-87 years (average 72); most were married and retired, five were professionals (remainder skilled-manual/unskilled).

Table 1. Reasons for exclusion from research participation

Reason for exclusion Number of patients

Patient declined 
Patient in denial / unaware of diagnosis/prognosis 3

Patient moved out of locality $\quad 1$

Patient deemed too unwell/distressed $\quad 12$

Patient had received curative treatment $\quad 1$

Patient did not have primary lung cancer $\quad 2$

\section{Data collection}

A pilot interview was conducted to test the appropriateness of questions, feasibility, duration of interviews and recruitment process (Addington-Hall et al., 2007). Data were then collected from 12 community patients diagnosed with advanced lung cancer who consented to participate in two semi-structured interviews (one month apart). Two participants were too unwell and unable to engage in their follow-up interviews. After capturing demographic data, an interview schedule (Table 2) which was informed by Llewellyn-Thomas' (1995) conceptual framework was administered. Llewellyn-Thomas (1995) incorporates the clinical context of decision-making; maps interactive elements that characterise decision-making; and takes account of how decision-making alters over time based on experiences of illness and 
interactions between patients, physicians, family carers and institutions. Pre-identified issues were discussed using probes and questions deemed relevant (Eatough and Smith, 2008). With consent, interviews were audio recorded and professionally transcribed verbatim. Each lasted 28 to 72 minutes (mean 48 minutes).

Table 2 Interview Schedule for Patient Interviews

1. Tell me about your diagnosis.

2. Tell me about choices or decisions you have made since the start of your illness.

3. When decisions had to be made, how involved were you in the process?

4. What influenced any decisions that you have made?

5. Do you think the right decisions have been made or do you have any regrets?

6. Given your current health, what are your hopes and priorities for your future treatment and care?

7. Tell me what you think the doctor is hoping to achieve with the treatment and care you are being given.

8. Tell me about conversations you have had about your preferences for future care.

9. If you needed cared for in the future, where would you prefer to be cared for, and what has influenced your decision?

10. Can you tell me what is like to talk about your wishes for the future?

11. What helps or hinders you to think or talk about the future? 
12. Do you think there are any gaps in how you have been treated? Would you like to recommend how care for patients with lung cancer could be improved?

\section{Data analysis}

Data analysis involved reading and re-reading; initial noting of exploratory, descriptive, linguistic and conceptual comments; developing emergent themes; and searching for connections across emergent themes using abstraction, polarization, contextualization and numeration (Smith et al., 2009). Academic supervisors representing sociology, social work and nursing independently applied and refined codes. Themes were compared and consensus was reached prior to exploring the data using Frank's (1995) narrative structures (restitution, chaos and quest). These were used to explore the patients' testimonies for connections across the 'pedagogy of suffering' (Frank, 1995: 145). The pedagogy of suffering means that 'one who suffers has something to teach...and thus has something to give' (Frank, 1995: 150). Relevant quotes were selected and pseudonyms were assigned to participants to preserve their anonymity.

\section{Findings}

Restitution narrative 
Frank (1995) suggests similarities between the restitution narrative and the 'departure stage' of Campbell's hero's journey (1972). Departure is the call that indicates to the patient, that something is not right which may be the development of a persistent cough, dizziness or the discovery of a suspicious lump, which echoes Frank's restitution narrative about tests, treatments, potential outcomes, competence of physicians, and metaphors about health. This includes how patients externalise the illness from their body with references to 'it'. Frank (1995: 83) suggests that a restitution narrative is based on two fundamental premises. Firstly that medicine has the power to cure and secondly, that anyone who experiences illness wants to be well again, which is evident within the findings from this study.

Within our sample, each participant's illness journey commenced with visits to their General Practitioner (GP) with seemingly innocent health complaints (suspected flu, persistent cough, weight loss or breathlessness) which initially resulted in prescriptions for anti-biotics or pain relief. According to Cassell (2004: 89), when subjective symptoms are reported by the patient, the 'doctor endeavours to find the disease that is causing the symptoms' and if that is not possible they prescribe medication to make the patient feel better. However, findings revealed that patients experienced repeated GP appointments or prescriptions prior to being referred to the hospital for tests, which created frustration and loss of faith in the competence and efficiency of the GP. Although he did not wish to blame anyone, Albert (patient ID1) did wonder if his illness would have been diagnosed sooner. 
'It was Christmas and there was a lot of flu about so I got prescribed pain killers twice or three times. It was maybe four or five weeks by the time I was sent for an Xray...there was a bit of a delay, I saw three doctors over the holidays and various things...I'm not saying it was anybody's fault, I'm just saying it was circumstances.'

Cassell (2004: 93) suggests that 'most sicknesses, even the dramatic ones, do not start with a bang.' Instead, illness is more likely to be determined by the gradual onset of symptoms, such as shortness of breath or a persistent cough, which was the case for Bobby (patient ID2) who indicated that he had been a lifelong smoker.

'I had a cough. I got an antibiotic and it didn't work so I rang again and they gave me another one [anti-biotic]. But when I rang for the third time the doctor wanted to see me and he sent me for a chest x-ray and they said they saw a shadow on my lung.'

In a minority of cases there was a 'bang' (Cassell, 2004: 93) when an ongoing health complaint developed into an acute problem, and patients presented at their local accident and emergency (A\&E) department where they were subsequently diagnosed. Irene (patient ID9) shared her experience of this:

'That day, I was at my mum's and it was lunchtime and all of a sudden, I just felt the need to spit and when I spat, there was blood. It scared me, but...I thought maybe it's nothing and thought I'd leave it until the morning to see the GP. Then later on I took 
the dog for a walk, the same thing again happened and I went up to A\&E. So we went to the hospital and I was seen by the triage nurse, taken quickly, they x-rayed me and obviously they immediately saw the lump or the tumour in my lung and admitted me'.

Deirdre (patient ID4) also recalled repeated visits to her GP surgery where she was prescribed pain relief for a suspected 'trapped nerve' and allegedly accused of being a hypochondriac. Following an emergency admission to hospital due to breathlessness she was diagnosed with malignant Mesothelioma. However, she felt haunted by the delay in her diagnosis and wondered why her illness had been missed by so many physicians.

'When they're putting the lid on me, I'll still be shouting, hold on a wee minute, there's something else I want to say to you, because at the back of my mind I would love to know. I know this sounds silly, but I'd just love to know why it wasn't caught sooner.'

Additionally, Deirdre repeatedly questioned why or how she had developed Mesothelioma as she had never smoked or worked in an industrial setting and she struggled to comprehend the seriousness of her diagnosis.

'I can honestly say that when the consultant said it, I didn't quite understand the severity of what he was saying. I knew people with asbestosis but they were shipyard men...it wasn't until the consultant said to me we can offer you chemo and it might keep it back for a while, that's when I really thought 'aha' and I cried that day.' 
For most patients, the consequences of a misdiagnosis were delayed tests or treatment, and limited treatment options from the outset. Hanna (patient ID8) believed that chemotherapy would buy her more time by slowing disease progression, or would improve her quality of life, but she was aware from the outset that her treatment was palliative.

'[Physician] at the beginning told me he couldn't cure it, but he could make it a bit easier for me which was through chemotherapy...Chemo was alright but hasn't done what it was supposed to...shrank it a bit, but didn't shrink it enough.'

The embodied (Sontag, 1978) and externalised (Frank, 1995) nature of Hanna's (patient ID8) cancer was acknowledged with repeated references to 'it' as she regarded the tumour or cancer as a living organism within her body, causing restrictions to her life and future. This was echoed by Albert (patient ID1) who referred to 'it' when he shared his resignation regarding limited treatment options due to his declining physical health.

'I have had radiotherapy but [Consultant] said that at the minute it [tumour] would be too big for chemotherapy and there is some doubt as to whether I...she thinks I'll need to be an awful lot more strong and so on before... at the minute she thinks it will do more harm than good. I just accepted the recommendation because I know myself I'm not that fit and strong.'

In Albert's narrative, he situates this decision and his acceptance within the present [at the minute], which may suggest hopes for future treatment if his overall health improves. 
Whereas Christine (patient ID3) had previously received treatment 10 years ago for bowel cancer, meaning that treatment choices for her newly diagnosed lung cancer were subsequently limited.

'Well the doctor said I can't have any more treatment, radiotherapy treatment, as I have had my quota. You see, I had 10 fractions of radiotherapy last time, but they told me I am not allowed more this time. They told me my treatment was palliative care'.

Within these restitution narratives the repeated GP appointments and delays in receiving tests or treatment suggest a lack of faith in the competence of the physicians. Decisions about treatment were influenced by the stage of disease, overall physical health and history of prior treatment. There was evidence of patients externalising their illness and trying to manage their emotional reactions to living with a life-limiting illness.

\section{Chaos narrative}

The chaos narrative is the opposite of restitution, as 'its plot imagines life never getting better' (Frank, 1995: 97). The chaos narrative lacks any coherent sequence, as the narrative is constantly interrupted, and patients struggle to find words to tell their story. Chaos narratives consist of vulnerability, futility and impotence, with the patient's 'loss of control' being complemented by the physician's 'inability to control the disease' (Frank: 1995: 100). Professionals need to utilise their interpersonal skills to tolerate the chaos as part of the life story (Frank, 1995: 111). 
Most patients struggled with the side effects of their chemotherapy treatment, which included nausea or sickness, diarrhoea, weight loss, low mood, fatigue and hair loss, which seemed to worsen with each cycle. Florence (patient ID 6) described it as 'going through hell due to the poison they pump into you.' Hanna (patient ID8) also found the chemotherapy treatment harrowing and frustrating:

'I've got so weak. I've lost an awful lot of fat off my body...I get terribly emotional. I know I can't do anything other than accept it. I done my five cycles of chemo thinking it would help. It did shrink it a bit but not a big lot.'

Others struggled with the side effects of the disease, which commonly caused breathlessness, loss of mobility and frailty. Deirdre (patient ID4) referred to the 'panic' she felt with breathing. Hanna (patient ID8) shared her frustration regarding reliance on prescribed medication and nasal oxygen.

'This has been the worst. The breathlessness has been terrible. It started about 13-14 weeks ago. I'm on drugs and I hate taking drugs, but what can I do? This [nasal oxygen] is on me $24 / 7$ and I never get rid of it.

Another common complaint was loss of mobility due to pain, breathlessness or physical frailty. Florence (patient ID6) was adjusting to a downstairs sleeping arrangement due to mobility issues. 
'I have a commode downstairs but I don't want to use that. I can climb stairs but someone has to come up behind me. We have a walk in shower, so I can have a shower. It's hard work getting upstairs, but it's worth it. Losing your independence is a bad thing, there is so little I can do now.'

Everyday tasks around the house or garden increased vulnerability, which resulted in loss of role and a reliance on others to do things. Irene (patient ID 9) described her own experiences as follows:

'I used to love gardening but bending down, I can't do that without coming up breathless. Everyone keeps following me around, which I find quite annoying. They're frightened I'm going to fall or whatever, but I'm so used to being independent and doing things on my own.'

According to Sontag (1978) most people diagnosed with cancer treat the disease as an evil, invincible predator curbing life expectancy. This was more obvious in follow-up interviews with changing perceptions of their illness and increased insight surrounding the inability of medical physicians to contain the disease. Initially Jean (patient ID7) had talked about 'beating' her illness whereas during follow-up she acknowledged having more 'bad days' and believed 'that ole cancer is letting me know it's going to get me.' Deirdre (patient ID4) believed her cancer had 'galloped away' emphasising the speed at which it had spread and curtailed life expectancy. Florence (patient ID6) knew her cancer had 'really spread' and 
expressed powerlessness and uncertainty about how this would impact on how physicians could manage pain and improve prognosis. At the initial interview Jean (patient ID7) walked her dog on the beach and John (patient ID10) enjoyed going to the gym, but during the follow-up interview they had lost their stamina and were forced to 'cut the cloth to suit.' At follow-up some had completely lost mobility resulting in them being confined to a wheelchair (Eddie patient ID5); a chair (Bobby patient ID2) or a bed (Florence patient ID6). For others, the impact was also apparent in terms of social interactions. Sympathy experienced in the early days shifted to 'awkward' communication with visitors wondering 'what will they find?' (Albert patient ID1) or the dwindling volume of hesitant callers who wondered 'is he dead yet?' (Eddie).

Despite early denial or refusal, most participants accepted their worst fears. Crossing this threshold led to the initiation stage or 'road of trials' (Campbell, 1972) experienced through emotional, social, physical, spiritual and financial sufferings (Frank, 1995: 118). Metaphors were used to describe their sufferings, vulnerability and impotence as the illness pervaded their bodies. Distressing narratives revealed frustrating losses to independence, invasions of privacy or dignity and social awkwardness and isolation. Acceptance was more evident at follow-up, which was coupled with increased awareness and insight into the physician's inability to contain their disease, leading to the quest narrative.

\section{Quest narrative}


The quest narrative shows how patients 'meet suffering head on' as they not only accept their illness but believe that something will be gained from their experiential journey (Frank, 1995). Quest stories involve reflexivity by the patient who has self-consciously transformed and has gained some insight from the experience, which they feel obliged to pass on to others. According to the final stage of 'return' (Campbell, 1972), the patient makes a heroic return from their suffering and agony and perseveres to share their enlightenment with others. However, for those living with a life-limiting illness, this return is temporary. According to Frank (1995: 120), the memoirs associated with the quest narrative can be described as an 'interrupted autobiography' where the illness constantly interrupts stories associated with the patient's past, present or future, which Bury (1982) characterised as 'biographical disruption' where the onset of disease disrupts plans and hopes for the future.

During the initial interview John (patient ID10) talked about how his treatment options were limited due to the nature of his illness and his reticence for surgery or chemotherapy based on the experiences of other friends. He also referred to societal fears of the 'big C'. However as he accepted his illness, he realised that being more open about his experience may help others.

'As I say I've had two or three friends who have had it [chemotherapy] and it's been really rough on them. They survived it all right but I don't know if I'd want to, unless you've got a good guarantee that...But that wouldn't be happening to me, as such, because you're not going to kill my cancer. They may delay it or they may reduce it 
but they're not going to kill it. I'm quite open about it [diagnosis]. I don't mind if people know about it because it helps actually when you speak to other people. But as well as that, the 'big C' was a thing I dreaded but now I'm living with it and other people see you, maybe if the same thing happens to others in the future it gives them encouragement, because you are bearing up under it.'

For all patients whose treatment was palliative from the outset was devastating but temporal awareness stemmed from insight into illness progression and mortality. This manifested itself in a number of ways. Some patients hoped to outlive their prognosis and wanted to enjoy every moment of life until they died. Eddie shared his hopes in the following:

'I am hoping the doctors got it wrong. I just want to live as long as possible now and hope to keep seeing my grandchildren. I just love them to bits. To get out in the wheelchair, on car trips and keep moving as long as I possibly can.'

Although most patients expressed a wish to die at home, surrounded by their family or pets, some feared becoming a burden to relatives. Eddie indicated that 'as long as [wife] is prepared to put up with me, I'm happy to be here at home.' Whereas Lawrence (patient ID12) expressed a preference to die in the hospice as he believed it would minimise the risk of burdening anyone. 
'I wouldn't like to be a burden on anyone. I think that there is a time that comes that you're just a burden and it would be much better to go...I feel lucky that I'm in here [hospice].'

When reflecting on her hopes for the future, Florence (patient ID6) wanted to have a 'peaceful death...free of pain.' She also indicated that she was 'a euthanasia supporter. I think people have a right to say when enough is enough.' Whereas others believed that you should and would not die before your time. Hanna (patient ID 8) referred to the importance of having faith in God but also believing that death would offer relief from her 'agony'.

'Nobody can tell you time, how long you've got. You'll not go a second before your time; I've seen that over the years. I've even sat with people at night praying for God to take them because they are in such agony. It's not going to be any different for me.'

This was echoed by David (patient ID11) who indicated that during discussions with his daughter, she told him that 'when your time comes dad, your time comes. There's nothing you can do about it.'

Participants who openly discussed dying during the research were usually more accepting of their fate and had initiated conversations about preferences and expectations around funerals with relatives. In some cases, participants were blocked from having these conversations and accused of being 'morbid' and reverted to creating a written record of their wishes. Jean (patient ID7) described her experience as follows: 
'I tried to tell my husband, brother and a couple of friends. My friend said for goodness sake that's far too morbid. I got a book. I couldn't stop writing and I called it "What if....?" When I told my mother and she said that's good.'

For other participants, avoiding emotional conversations with loved ones resulted in letters of instructions being left on the mantel piece or assumptions that relatives would 'know' what they wanted.

Although their biographical disruption (Bury, 1982) was coupled with a sense of sadness and tragedy for wives or husbands facing 'widowhood' and for parents who would not see their children or grandchildren reach important milestones, most participants managed to put their legal and financial affairs in order to ensure that their spouse 'would have nothing to worry about' (Hanna patient ID8) or that children 'would be reasonably well catered for in terms of education' (Albert patient ID1). Others who initiated conversations regarding the future were motivated by a wish to redistribute personal belongings which held meaning or to ensure that treasured pets would be well cared for in the future. Hanna (patient ID8) gave instructions for each relative to remove any item they had originally given to her as that would make her happy, and Irene (patient ID9) wanted to ensure that her dog would get walked on the beach every day. Whereas Lawrence (patient ID12) missed natural opportunities to share his wishes as he was unsure how and when to broach the subject with his nephews in case they thought his death was imminent. 
Although most knew their legacy would continue through spouses or children, there were two who hoped their legacy to continue through charitable acts. Deirdre (patient ID4) expressed a wish to donate her body to the local University for scientific research into cancer. Florence's (patient ID6) children named a star after her and her granddaughter promised to do a sponsored walk each year in her memory.

As illustrated in this quest section, all quest stories express three ethics - recollection, solidarity and inspiration - which overlap and demonstrate the diversity of the responsibility in storytelling (Frank, 1995: 133). All experienced the devastating blow from the outset that their illness was not curative which eventually led to acceptance. Some were determined to enjoy life with loved ones until they died. Most shared preferences for place of death or funeral wishes with others, whether this was face-to-face or in written form. Amidst the suffering and tragedy of leaving loved ones, it was important for the 'hero' to return and put financial or legal affairs in order or to leave a legacy. As Frank suggests, 'ill people need to be regarded by themselves, by their caregivers, and by our culture as heroes of their own stories' (Frank, 1995: 134). Although patients in these findings heroically persevered through their suffering and illness and self-consciously transformed, there was still evidence of an interrupted autobiography, where multiple losses were mourned, either for themselves or for others, and uncertainty was experienced regarding how their illness would progress.

\section{Discussion}


The aim of this study was to use Frank's (1995) narrative structures to undertake an in-depth exploration of the 'pedagogy of suffering' of patients with advanced lung cancer during the last few months of their lives. Findings highlighted within the 'restitution narratives' (Frank, 1995) revealed repeated visits to the GP with seemingly innocent health complaints prior to receiving tests, diagnosis or treatment, which left patients feeling frustrated and wondering if a more timely diagnosis would have altered their prognosis. Given the prevalence of lung cancer in Northern Ireland (NICR, 2013) and the medical history of most patients, it is not surprising that patients lost faith in their medical physician. If prompt access to chest x-rays had been facilitated for patients who presented with a persistent cough or pain that was unresponsive to prescribed medication, perhaps an accurate diagnosis could have been confirmed earlier.

Although most patients recalled being involved in treatment decision-making conversations, their co-morbidities, deteriorating health or perceived risks tended to dictate decisions. Siminoff et al. (2006) reported that palliative treatment decisions are fraught with balancing side-effects, quality of life and possible risks. Findings highlight the importance of ensuring that factors influencing the decision-making process are fully explained and that patients are adequately supported with the side effects of treatment and their disease.

Within the 'chaos narratives' (Frank, 1995) references to the embodied nature of cancer were evident across the sample, with patients externalising their disease with references to 'it', which was in keeping with published literature (Sontag, 1978; Frank, 1995). Rutherford et al. 
(2008) previously emphasised the loss, insecurity, vulnerability and unfamiliarity that impact on everyday life for patients with lung cancer. This was also evident in our 'chaos narratives' where patient narratives revealed emotional battles with a range of physical symptoms provoked by illness, which impacted on body image, social relations, physical world and role within the family home. Additionally, the abominations of the body (Goffman, 1963); adjustments in lifestyle (Marks et al., 2011); and quiet heroism (Kleniman, 1989) were all aspects of suffering that made patients' lives feel more burdened. According to O'Grady et al. (2012) providing patients with psychological support during the 'road of trials' (Campbell, 1972) and 'pedagogy of suffering' (Frank, 1995) is an important role for health and social care professionals. However, given the staff shortages and excessive caseloads, routinely offering psychosocial support is becoming increasingly difficult, despite it being pivotal to facilitating closure in end of life care (Baker, 2006). Furthermore, amidst medical decisions about treatment and end-of-life care it is important that social work professionals are enabled to support patients with the everyday compromises and decisions that pervade the lives of patients and their family caregivers.

Findings outlined under the 'quest narrative' (Frank, 1995) highlighted the enormity of loss and 'biographical disruption' (Bury, 1982) experienced by patients as over time they made the transition from 'closed' to 'open' awareness (Glaser and Strauss, 1965). Where this transition occurred patients shared fears of dying in agony, explored immediate priorities regarding pet care, redistribution of personal belongings and funeral preferences and 
expressing their future hopes (Martin et al., 2000; Briggs, 2003) all of which could be explored by social work staff. Where patients were prevented from talking about their impending death with loved ones they reverted to written forms of communication to ensure their wishes were known. Despite their physical biographies reminding them of their mortality (Durkheim, 1961) others missed natural opportunities and regretted not discussing their preferences for the future with close family.

Sontag (1978) describes cancer as the invincible predator, curbing life expectancy and mirroring society's fears about the 'big C' and death as a 'taboo' topic (McIlfatrick et al., 2014). Such fears and taboos were acknowledged within the context of patients making a temporary 'heroic return' (Campbell, 1972) from their suffering to enlighten others about the life-limiting illness journey. Whilst most patients seemed to accept the devastating blow of their fate, the preciousness of time was acknowledged and patients remained keen to outlive their prognosis so that they could enjoy quality time with their loved ones. The need to respect time as ordered, sequential and one directional has been acknowledged within the literature (Rabinach, 1992; Wahidin, 2004).

These findings highlight how important it is that social work professionals spend time building relationships with patients to explore their values and explore what illness, life and death means to a person, which is emphasised by Winkler et al. (2013) and supports the goals, hopes and preparation for end-of-life care advocated by Advance Care Planning (Martin et al., 2000; Briggs, 2003). Given the focus on biographical disruption (Bury, 1982) 
and promoting patient narratives (Frank, 1995), this potential area of unmet need could be addressed by generalist and specialist palliative care social work staff to ensure that the multiple losses and psychosocial needs of patients facing end of life are being routinely addressed.

\section{Conclusion}

The 'pedagogy of suffering' contributes to the growing body of evidence available in relation to the lived experiences of patients with advanced lung cancer and highlights what we can learn from patient narratives. The findings emphasise the consequences of unnecessary delays and the preciousness of time for patients and professionals. Patients with life-limiting illness suffer a range of losses, which impact on different life domains and need to be skilfully explored. Opportunities to explore psychosocial needs and Advance Care Planning should be facilitated and revisited by all health and social care professionals to capture changing values, preferences and priorities of patients and their family caregivers. Psychological and spiritual needs should also be explored, taking into consideration their religious beliefs, family support network and fears about dying alone or in pain. In keeping with the global definition of social work (IFSW, 2014) structures and processes should be in place to support individuals with such devastating life challenges from the point of being diagnosed with a life- limiting illness.

\section{Limitations}


This study has several limitations. As a qualitative study, the sample size was small.

However, the sample size was in keeping with the method used for data analysis, and the findings provide rich insights into the lived experiences and sufferings of patients diagnosed with advanced lung cancer. Recruiting patients from one Health and Social Care Trust in Northern Ireland resulted in patients being from one cultural background. Similarly, it was not possible to gain access to minority cultural backgrounds and non-English speaking patients. Therefore it is not possible to generalise the findings to other cultural backgrounds living within Northern Ireland.

\section{References}

Addington-Hall, J., Bruera, E., Higginson, I.J., \& Payne, S. (2007) Research methods in Palliative Care, Oxford, Oxford University Press.

Baker, M. (2006) 'Facilitating forgiveness and peaceful closure: The therapeutic value of psychosocial intervention', Journal of Social Work in End of Life and Palliative Care, 1(4), pp. 83-96.

Bekker, H.L. (2009) 'Using decision-making theory to inform clinical practice' in A, Edwards, \& G. Elwyn (Eds.), Shared decision-making in health care ( $2^{\text {nd }}$ edition) (pp. 4551). Oxford, UK, Oxford University Press. 
Briggs, L. (2003) 'Shifting the focus of advance care planning: using an in-depth interview to build and strengthen relationships', Journal of Palliative Medicine, 7, pp. 341-349.

Bury, M. (1982) 'Chronic illness as biographical disruption', Sociology of Health and Illness, 4(2), pp. 167-182.

Campbell, J. (1972) The hero with a thousand face. Princeton: Princeton University Press.

Cancer Research UK and World Health Organisation. (2015). World Cancer Factsheet.

Retrieved from

http://publications.cancerresearchuk.org/downloads/Product/CS_REPORT_WORLD.pdf

Cancer Research UK. (2016) Cancer Mortality. Retrieved from

http://publications.cancerresearchuk.org/cancerstats/stats mortality

Cassell, E.J. (2004) The nature of suffering and the goals of medicine, (2 ${ }^{\text {nd }}$ edition)

Oxford, Oxford University Press.

Department of Health. (2008) End of Life Care Strategy - Promoting High Quality

Care for all Adults at the End of Life, London: Department of Health. Retrieved from

http://www.dh.gov.uk/en/Publicationsandstatistics/Publications/PublicationsPolicyAnd

\section{Guidance/DH_086277}

Deschepper, R., Bernheim, J.L,, Stichele, R.V., van den Block,L., Michiels, E., van der Kelen, G., Mortier, F., \& Deliens, L. (2007) 'Truth-telling at the end of life: a pilot study on the perspective of patients and professional caregivers', Patient Education and Counseling, 71, pp. 52-56. 
Desharnais, S., Carter, R.E., Hennessy, W., Kurent, J.E., \& Carter, C. (2007) 'Lack of concordance between physician and patient: reports on end of life care discussions', Journal of Palliative Medicine, 10(3), pp. 728-740.

Durkheim, E. (1961) The Elementary Forms of the Religious Life. New York, CollierMacmillan.

Eatough, V., \& Smith, J.A. (2008) 'Interpretative Phenomenological Analysis' in C. Willig \& W. Stainton-Rogers (Eds.), The Sage Handbook of Qualitative Research in Psychology (part I). London, Sage Publications.

Elwyn, G., Edwards, A., Kineersley, P., \& Grol, R. (2000) 'Shared decision making and the concept of equipoise: the competences involving patients in healthcare choices', British Journal of General Practice, 50, pp. 892-897.

Frank, A. (1995) The Wounded Storyteller: Body, illness and ethics. Chicago, University of Chicago Press.

Glaser, B.G., \& Strauss, A.L. (1965) 'Closed Awareness' in B. G. Glaser \& A.L. Strauss (Eds.), Awareness of Dying (pp. 29-46). Chicago, Aldine Publishing Company.

Goffman, E. (1963) Stigma: Notes on the Management of Spoiled Identity. New Jersey, Penguin Books. 
International Federation of Social Work (2014) Global definition of Social Work, agreed at the IASSW General Assembly, http://ifsw.org/get-involved/global-definition-of-social-work/

Kleinman, A. (1989) The Illness Narratives: Suffering, healing and the human condition. New York, Basic Books.

Llewellyn-Thomas, H.A. (1995) 'Patients' health-care decision making: A framework for descriptive and experimental investigations’ Medical Decision Making, 5(2), pp. 101-106.

Marks, D.F., Murray, M., Evans, B., \& Estacio, E.V. (2011) Health Psychology: theory, Research and Practice ( ${ }^{\text {rd }}$ edition), London, UK, Sage.

Martin, D.K., Emmanuel, L.L., \& Singer, P.A. (2000) 'Planning for the end of life', Lancet, 356, pp. 1672-1676.

McIlfatrick, S., Noble, H., McCorry, N.K., Roulston, A., Hasson, F., McLaughlin, D., Johnston, G., Rutherford, L., Payne, C., Kernohan, G., Kelly, S., \& Craig, A. (2014) 'Exploring public awareness and perceptions of palliative care: a qualitative study' Palliative Medicine, 28(3), pp. 273-280.

McLeod, J. (2001) Qualitative research in counselling and psychotherapy. London, Sage. Northern Ireland Cancer Registry. (2016) Cancer Statistics by Health Trust. Retrieved from $\quad$ http://www.qub.ac.uk/research-centres/nicr/CancerInformation/officialstatistics/ByGeography/HealthTrust/ 
Northern Ireland Cancer Registry. (2015) Lung Cancer: Cancer in Northern Ireland 2013.

Retrieved from http://www.qub.ac.uk/research-

centres/nicr/FileStore/PDF/FactSheets/Filetoupload,531396,en.pdf

O’Grady, E., Dempsey, L., \& Fabby, C. (2012) ‘Anger: a common form of psychological distress among patients at the end of life' International Journal of Palliative Nursing, 18(12), pp. 592-596.

Rabinach, A. (1992) The Human Motor: Energy, fatigue and origins of modernity. California, University of California Press.

Ramondetta, L.M., Tortolero-Luna, G., Bodurka, D.C., Sills, D., Basenengquist, K., Gano, J., \& Levenback, C. (2004) 'Approaches for end of life care in the field of gynaecologic oncology: an exploratory study', International Journal of Gynaecological Cancer, 14, pp. $580-588$.

Rutherford, L., McAuley, J., \& Fitzsimons, D. (2008). Patients' and carers' experiences of living with lung cancer. Report for Macmillan Cancer Support, 2008. Belfast: MacMillan and Belfast Health and Social Care Trust.

Siminoff, L.A,, Rose, J.H., Zhang, A. \& Zyzanski, J. (2006) 'Measuring discord in treatment decision-making; progress toward development of a cancer communication and decisionmaking assessment tool' Psychooncology, 15, pp. 528-540. 
Smith, J.A., Flowers, P., \& Larkin, M. (2009) Interpretative Phenomenological Analysis: Theory, method and research. London, UK, Sage Publications.

Sontag, S. (1978) Illness as a Metaphor. New York, Farrar, Strauss and Giroux.

Wahidin, A. (2004) Older women in the criminal justice system: running out of time, London and Philadelphia: Jessica Kingsley Publishers.

Willard, C. \& Luker, K. (2006) 'Challenges to end of life care in the acute hospital setting', Palliative Medicine, 20, pp. 611-615.

Winkler, E.C., Hiddenmann, W., \& Marckmann, G. (2013) 'Evaluating a patient's request for life-prolonging treatment: an ethical framework' Journal of Medical Ethics, 38, pp. 647-651. 